\title{
RW-CLOSED MAPS AND RW-OPEN MAPS IN TOPOLOGICAL SPACES
}

\author{
M.Karpagadevi, \\ Karpagam College of Engineering, \\ Coimbatore, India
}

\author{
A.Pushpalatha \\ Government Arts College, \\ Udumalpet, India
}

\begin{abstract}
In this paper we introduce rw-closed map from a topological space $\mathrm{X}$ to a topological space $\mathrm{Y}$ as the image of every closed set is rw-closed and also we prove that the composition of two rw-closed maps need not be rw-closed map. We also obtain some properties of rw-closed maps.
\end{abstract}

Mathematics Subject Classification: 54C10

Keywords: rw-closed maps, rw-open maps.

\section{INTRODUCTION}

Generalized closed mappings were introduce and studied by Malghan[5].wg-closed maps and rwgclosed maps were introduced and studied by Nagaveni[6].Regular closed maps,gpr-closed maps and rg-closed maps have been introduced and studied by Long[4], Gnanambal[3] and Arockiarani[1] respectively.

In this paper, a new class of maps called regular weakly closed maps ( briefly, rw-closed) maps have been introduced and studied their relations with various generalized closed maps. We prove that the composition of two rw-closed maps need not be rwclosed map. We also obtain some properties of rw-closed maps.

S.S. Benchalli and R.S Wali [2] introduced new class of sets called regular weakly - closed (briefly rw - closed) sets in topological spaces which lies between the class of all $\mathrm{w}$ - closed sets and the class of all regular $\mathrm{g}$ - closed sets.

Throughout this paper $(\mathrm{X}, \tau)$ and $(\mathrm{Y}, \sigma)$ (or simply $\mathrm{X}$ and $\mathrm{Y}$ ) represents the non-empty topological spaces on which no separation axiom are assumed, unless otherwise mentioned. For a subset $\mathrm{A}$ of $\mathrm{X}, \operatorname{cl}(\mathrm{A})$ and $\operatorname{int}(\mathrm{A})$ represents the closure of $\mathrm{A}$ and interior of $\mathrm{A}$ respectively.

\section{PRELIMINARIES}

In this section we recollect the following basic definitions which are used in this paper.

Definition 2.1 [2]: A subset A of a topological space $(\mathrm{X}, \tau)$ is called rw-closed (briefly rw-closed) if $\mathrm{cl}(\mathrm{A})$ $\subseteq \mathrm{U}$, whenever $\mathrm{A} \subseteq \mathrm{U}$ and $\mathrm{U}$ is regular semiopen in $\mathrm{X}$.

Definition 2.2 [7]: A subset A of a topological space $(\mathrm{X}, \tau)$ is called regular generalized closed (briefly rgclosed) if $\mathrm{cl}(\mathrm{A}) \subseteq \mathrm{U}$ whenever $\mathrm{A} \subseteq \mathrm{U}$ and $\mathrm{U}$ is regular open in $\mathrm{X}$.
Definition 2.3 [9]: A subset A of a topological space $(\mathrm{X}, \tau)$ is called weakly closed (briefly w-closed) if $\mathrm{cl}(\mathrm{A})) \subseteq \mathrm{U}$ whenever $\mathrm{A} \subseteq \mathrm{U}$ and $\mathrm{U}$ is semi open in $\mathrm{X}$.

Definition 2.4 [7] :A map f: $(\mathrm{X}, \tau) \rightarrow(\mathrm{Y}, \sigma)$ from a topological space $\mathrm{X}$ into a topological space $\mathrm{Y}$ is called $\mathrm{rg}$ continuous if the inverse image of every closed set in $\mathrm{Y}$ is rg-closed in $\mathrm{X}$.

Definition 2.5 [9] :A map f: $(\mathrm{X}, \tau) \rightarrow(\mathrm{Y}, \sigma)$ from a topological space $\mathrm{X}$ into a topological space $\mathrm{Y}$ is called $\mathrm{W}$-continuous if the inverse image of every closed set in $\mathrm{Y}$ is $\mathrm{w}$-closed in $\mathrm{X}$.

Definition 2.6 [5]: A map f: $(\mathrm{X}, \tau) \rightarrow(\mathrm{Y}, \sigma)$ is called g-closed if $\mathrm{f}(\mathrm{F})$ is g-closed in

$(Y, \sigma)$ for every closed set $F$ of $(X, \tau)$.

Definition 2.7 [8]: A map f: $(\mathrm{X}, \tau) \rightarrow(\mathrm{Y}, \sigma)$ is called w-closed if $\mathrm{f}(\mathrm{F})$ is w-closed in

$(\mathrm{Y}, \sigma)$ for every closed set $\mathrm{F}$ of $(\mathrm{X}, \tau)$.

Definition 2.8 [1]:A map f: $(\mathrm{X}, \tau) \rightarrow(\mathrm{Y}, \sigma)$ is called rg-closed if $\mathrm{f}(\mathrm{F})$ is rg-closed in $(\mathrm{Y}, \sigma)$ for every closed set $F$ of $(X, \tau)$.

Definition 2.9 [10]:A map f: $(X, \tau) \rightarrow(Y, \sigma)$ is called g-open if $f(U)$ is g-open in $(Y, \sigma)$ for every open set $\mathrm{U}$ of $(\mathrm{X}, \tau)$.

Definition 2.10 [8]:A map f: $(\mathrm{X}, \tau) \rightarrow(\mathrm{Y}, \sigma)$ is called w-open if $\mathrm{f}(\mathrm{U}) \mathrm{w}$-open in $(\mathrm{Y}, \sigma)$ for every open set $\mathrm{U}$ of $(\mathrm{X}, \tau)$.

Definition 2.11[1]: A map f: $(X, \tau) \rightarrow(Y, \sigma)$ is called rg-open if $f(U)$ rg-open in $(Y, \sigma)$ for every open set $U$ of $(X, \tau)$.

\section{Rw-closed maps}

We introduce the following definition 
Definition : 3.1 A map $\mathrm{f}:(\mathrm{X}, \tau) \rightarrow(\mathrm{Y}, \sigma)$ is said to be regular weakly (briefly rw-closed) if the image of every closed set in $(\mathrm{X}, \tau)$ is rw-closed in $(\mathrm{Y}, \sigma)$

Theorem: 3.2 Every closed map is rw-closed map but not conversely.

Proof: The proof follows from the definitions and fact that every closed set is rw-closed.

Remark: 3.3 The converse of the above theorem need not be true as seen from the following example.

Example : 3.4 Consider $\mathrm{X}=\mathrm{Y}=\{\mathrm{a}, \mathrm{b}, \mathrm{c}\}$ with topologies $\tau=\{\mathrm{X}, \phi,\{\mathrm{c}\}\}$ and $\sigma=\{\mathrm{Y}, \phi,\{\mathrm{a}\}$, $\{b\},\{a, b\}\}$. Let $f:(X, \tau) \rightarrow(Y, \sigma)$ be the identity map. Then this function is rw-closed but not closed as the image of closed set $\{a, b\}$ in $X$ is $\{a, b\}$ which is not closed set in $\mathrm{Y}$.

Theorem: 3.5 Every rw-closed map is rg-closed map but not conversely.

Proof: The proof follows from the definitions and fact that every rw-closed set is rg-closed.

Remark: 3.6 The converse of the above theorem need not be true as seen from the following example.

Example : 3.7 Consider $\mathrm{X}=\mathrm{Y}=\{\mathrm{a}, \mathrm{b}, \mathrm{c}, \mathrm{d}\}$ with topologies $\tau=\{\mathrm{X}, \phi,\{\mathrm{b}\},\{\mathrm{a}, \mathrm{b}, \mathrm{d}\}\}$ and

$\sigma=\{\mathrm{Y}, \phi,\{\mathrm{a}\},\{\mathrm{b}\},\{\mathrm{a}, \mathrm{b}\},\{\mathrm{a}, \mathrm{b}, \mathrm{c}\}\}$. Let $\mathrm{f}:(\mathrm{X}, \tau) \rightarrow$ $(\mathrm{Y}, \sigma)$ be the identity map. Then this function is $\mathrm{rg}$ closed but not rw-closed as the image of closed set $\{\mathrm{c}\}$ in $\mathrm{X}$ is $\{\mathrm{c}\}$ which is not rw-closed set in Y.

Theorem: 3.8 Every w-closed map is rw-closed map but not conversely.

Proof: The proof follows from the definitions and fact that every w-closed set is rw-closed.

Remark: 3.9 The converse of the above theorem need not be true as seen from the following example.

Example: 3.10 Consider $\mathrm{X}=\mathrm{Y}=\{\mathrm{a}, \mathrm{b}, \mathrm{c}\}$ with topologies $\tau=\{\mathrm{X}, \phi,\{\mathrm{c}\}\}$ and $\sigma=\{\mathrm{Y}, \phi, \quad\{\mathrm{a}\}$, $\{b\},\{a, b\}\}$. Let $\mathrm{f}:(\mathrm{X}, \tau) \rightarrow(\mathrm{Y}, \sigma)$ be the identity map. Then this function is rw-closed but not w-closed as the image of closed set $\{a, b\}$ in $X$ is $\{a, b\}$ which is not closed set in Y.

Theorem: 3.11 A map f: $(\mathrm{X}, \tau) \rightarrow(\mathrm{Y}, \sigma)$ is rw-closed if and only if for each subset $\mathrm{S}$ of $(\mathrm{Y}, \sigma)$ and each open set $\mathrm{U}$ containing $\mathrm{f}^{-1}(\mathrm{~S}) \subset \mathrm{U}$, there is a rw-open set of $(Y, \sigma)$ such that $S \subset V$ and $f^{-1}(V) \subset U$.

Proof: Suppose $\mathrm{f}$ is rw-closed. Let $\mathrm{S} \subset \mathrm{Y}$ and $\mathrm{U}$ be an open set of $(X, \tau)$ such that $f^{-1}(S) \subset U$. Now $X-U$ is closed set in $(X, \tau)$. Since $f$ is rw-closed, $f(X-U)$ is rwclosed set in $(Y, \sigma)$. Then $\mathrm{V}=\mathrm{Y}-\mathrm{f}(\mathrm{X}-\mathrm{U})$ is a rw-open set in $(Y, \sigma)$. Note that $f^{-1}(S) \subset U$ implies $S \subset V$ and $f$ ${ }^{-1}(\mathrm{~V})=\mathrm{X}-\mathrm{f}^{-1}(\mathrm{f}(\mathrm{X}-\mathrm{U})) \subset \mathrm{X}-(\mathrm{X}-\mathrm{U})=\mathrm{U}$. That is $\mathrm{f}^{-1}(\mathrm{~V})$ $\subset \mathrm{U}$.

For the converse, let $\mathrm{F}$ be a closed set of $(X, \tau)$. Then $f^{-1}\left(f(F)^{c}\right) \subset F^{c}$ and $F^{c}$ is an open set in $(\mathrm{X}, \tau)$. By hypothesis, there exists a rw-open set $\mathrm{V}$ in
$(\mathrm{Y}, \sigma)$ such that $\mathrm{f}(\mathrm{F})^{\mathrm{c}} \subset \mathrm{V}$ and $\mathrm{f}^{-1}(\mathrm{~V}) \subset \mathrm{F}^{\mathrm{c}}$ and so $\mathrm{F} \subset$ $\left(\mathrm{f}^{-1}(\mathrm{~V})\right)^{\mathrm{c}}$. Hence $\mathrm{V}^{\mathrm{c}} \subset \mathrm{f}(\mathrm{F}) \subset \mathrm{f}\left(\left(\left(\mathrm{f}^{-1}(\mathrm{~V})\right)^{\mathrm{c}}\right) \subset \mathrm{V}^{\mathrm{c}}\right.$ which implies $\mathrm{f}(\mathrm{V}) \subset \mathrm{V}^{\mathrm{c} .}$ Since $\mathrm{V}^{\mathrm{c}}$ is rw-closed, $\mathrm{f}(\mathrm{F})$ is rwclosed. That is $f(F)$ rw-closed in $(Y, \sigma)$ and therefore $f$ is rw-closed.

Remark: 3.12 The composition of two rw-closed maps need not be rw-closed map in general and this is shown by the following example.

Example: 3.13 Consider $\mathrm{X}=\mathrm{Y}=\{\mathrm{a}, \mathrm{b}, \mathrm{c}\}$ with topologies $\tau=\{\mathrm{X}, \phi,\{\mathrm{b}\},\{\mathrm{a}, \mathrm{b}\}\}, \sigma=\{\mathrm{Y}, \phi, \quad\{\mathrm{a}\}$, $\{\mathrm{b}\},\{\mathrm{a}, \mathrm{b}\}\}, \eta=\{\mathrm{Z}, \phi, \quad\{\mathrm{a}\},\{\mathrm{c}\},\{\mathrm{a}, \mathrm{c}\}\}$. Define f: $(\mathrm{X}, \tau) \rightarrow(\mathrm{Y}, \sigma)$ by $\mathrm{f}(\mathrm{a})=\mathrm{a}, \mathrm{f}(\mathrm{b})=\mathrm{b}$ and $\mathrm{f}(\mathrm{c})=\mathrm{c}$ and $\mathrm{g}:$ $(\mathrm{Y}, \sigma) \rightarrow(\mathrm{Z}, \eta)$ be the identity map. Then $\mathrm{f}$ and $\mathrm{g}$ are rw-closed maps but their composition $\mathrm{g}^{\circ} \mathrm{f}:(\mathrm{X}, \tau)$ $\rightarrow(Z, \eta)$ is not rw-closed map because $\mathrm{F}=\{\mathrm{c}\}$ is closed in $(X, \tau)$ but $\mathrm{g}^{\circ} \mathrm{f}(\{\mathrm{a}\})=\mathrm{g}(\mathrm{f}(\{\mathrm{c}\}))=\mathrm{g}(\{\mathrm{c}\})=$ $\{c\}$ which is not rw-closed in $(Z, \eta)$.

Theorem: 3.14 If $\mathrm{f}:(\mathrm{X}, \tau) \rightarrow(\mathrm{Y}, \sigma)$ is closed map and $g:(Y, \sigma) \rightarrow(Z, \eta)$ is rw-closed map, then the composition $\mathrm{g}^{\circ} \mathrm{f}:(\mathrm{X}, \tau) \rightarrow(\mathrm{Z}, \eta)$ is rw-closed map.

Proof: Let $F$ be any closed set in $(X, \tau)$. Since $f$ is closed map, $\mathrm{f}(\mathrm{F})$ is closed set in $(\mathrm{Y}, \sigma)$. Since $\mathrm{g}$ is rwclosed map, $g(f(F))$ is rw-closed set in $(Z, \eta)$. That is $\mathrm{g}^{\circ} \mathrm{f}(\mathrm{F})=\mathrm{g}(\mathrm{f}(\mathrm{F}))$ is rw-closed and hence $\mathrm{g}{ }^{\circ} \mathrm{f}$ is rwclosed map.

Remark: 3.15 If $\mathrm{f}:(\mathrm{X}, \tau) \rightarrow(\mathrm{Y}, \sigma)$ is rw-closed map and $g:(Y, \sigma) \rightarrow(Z, \eta)$ is closed map, then the composition need not be rw-closed map as seen from the following example.

Example: 3.16 Consider $\mathrm{X}=\mathrm{Y}=\mathrm{Z}=\{\mathrm{a}, \mathrm{b}, \mathrm{c}\}$ with topologies $\tau=\{\mathrm{X}, \phi,\{\mathrm{b}\},\{\mathrm{a}, \mathrm{b}\}\}, \sigma=\{\mathrm{Y}, \phi, \quad\{\mathrm{a}\}$, $\{\mathrm{b}\},\{\mathrm{a}, \mathrm{b}\}\}, \eta=\{\mathrm{Z}, \phi, \quad\{\mathrm{a}\},\{\mathrm{c}\},\{\mathrm{a}, \mathrm{c}\}\}$. Define $\mathrm{f}$ : $(\mathrm{X}, \tau) \rightarrow(\mathrm{Y}, \sigma)$ by $\mathrm{f}(\mathrm{a})=\mathrm{a}, \mathrm{f}(\mathrm{b})=\mathrm{b}$ and $\mathrm{f}(\mathrm{c})=\mathrm{c}$ and $\mathrm{g}:$ $(\mathrm{Y}, \sigma) \rightarrow(\mathrm{Z}, \eta)$ be the identity map. Then $\mathrm{f}$ is rwclosed map and $g$ is a closed map but their composition $\mathrm{g}^{\circ} \mathrm{f}:(\mathrm{X}, \tau) \rightarrow(\mathrm{Z}, \eta)$ is not rw-closed map since for the closed set $\{\mathrm{c}\}$ in $(\mathrm{X}, \tau)$ but $\mathrm{g}{ }^{\circ} \mathrm{f}(\{\mathrm{c}\})$ $=\mathrm{g}(\mathrm{f}(\{\mathrm{c}\}))=\mathrm{g}(\{\mathrm{c}\})=\{\mathrm{c}\}$ which is not rw-closed in $(\mathrm{Z}, \eta)$.

Theorem: 3.17 Let $(X, \tau),(Z, \eta)$ be topological spaces and $(\mathrm{Y}, \sigma)$ be topological spac where every rw-closed subset is closed. Then the composition $\mathrm{g}^{\circ} \mathrm{f}:(\mathrm{X}, \tau) \rightarrow$ $(\mathrm{Z}, \eta)$ of the rw-closed maps $\mathrm{f}:(\mathrm{X}, \tau) \rightarrow(\mathrm{Y}, \sigma)$ and $\mathrm{g}$ $:(Y, \sigma) \rightarrow(Z, \eta)$ is rw-closed.

Proof: Let A be a closed set of $(X, \tau)$. Since $f$ is rwclosed, $\mathrm{f}(\mathrm{A})$ is rw-closed in $(\mathrm{Y}, \sigma)$. Then by hypothesis $\mathrm{f}(\mathrm{A})$ is closed. Since $\mathrm{g}$ is rw-closed, $\mathrm{g}(\mathrm{f}(\mathrm{A}))$ is rwclosed in $(Z, \eta)$ and $g(f(A))=g{ }^{\circ} f(A)$. Therefore $g{ }^{\circ}$ $\mathrm{f}$ is rw-closed.

Theorem: 3.18 If $\mathrm{f:}(\mathrm{X}, \tau) \rightarrow(\mathrm{Y}, \sigma)$ is g-closed, $\mathrm{g}$ : $(\mathrm{Y}, \sigma) \rightarrow(\mathrm{Z}, \eta)$ be rw-closed and $(\mathrm{Y}, \sigma)$ is $\mathrm{T}_{1 / 2}-$ space then their composition $\mathrm{g}^{\circ} \mathrm{f}:(\mathrm{X}, \tau) \rightarrow(\mathrm{Z}, \eta)$ is rwclosed map.

Proof: Let $A$ be a closed set of $(X, \tau)$. Since $f$ is $g$ closed, $f(A)$ is g-closed in $(Y, \sigma)$. Since $g$ is rwclosed, $g(f(A))$ is rw-closed in $(Z, \eta)$ and $g(f(A))=g$ ${ }^{\circ} \mathrm{f}(\mathrm{A})$. Therefore $\mathrm{g}{ }^{\circ} \mathrm{f}$ is rw-closed.

Theorem: 3.19 Let $\mathbf{f}:(X, \tau) \rightarrow(Y, \sigma)$ and $g:$ $(\mathrm{Y}, \sigma) \rightarrow(\mathrm{Z}, \eta)$ be two mappings such that their 
composition $\mathrm{g} \circ \mathrm{f}:(\mathrm{X}, \tau) \rightarrow(\mathrm{Z}, \eta)$ be rw-closed mapping. Then the following statements are true.

i) If $\mathrm{f}$ is continuous and surjective, then $\mathrm{g}$ is rw-closed

ii) If $\mathrm{g}$ is rw-irresolute and injective, then $\mathrm{f}$ is rw-closed.

iii) If $\mathrm{f}$ is g-continuous, surjective and $(\mathrm{X}, \tau)$ is a $\mathrm{T}_{1 / 2}$ - space, then $\mathrm{g}$ is rwclosed.

Proof: i) Let $A$ be a closed set of $(Y, \sigma)$. Since $f$ is continuous, $\mathrm{f}^{-1}(\mathrm{~A})$ is closed in

$\mathrm{g}^{\circ} \mathrm{f}\left(\mathrm{f}^{-1}(\mathrm{~A})\right)$ is rw-closed in $(\mathrm{Z}, \eta)$. That is $\mathrm{g}(\mathrm{A})$ is rwclosed in $(Z, \eta)$, since $f$ is surjective. Therefore $g$ is rwclosed.

ii) Let $\mathrm{B}$ be a closed set of $(\mathrm{X}, \tau)$. Since $\mathrm{g}{ }^{\circ} \mathrm{f}$ is rwclosed, $\mathrm{g}^{\circ} \mathrm{f}(\mathrm{B})$ is rw-closed in $(\mathrm{Z}, \eta)$.

Since $g$ is rw-irresolute, $g^{-1}\left(g^{\circ} \mathrm{f}(\mathrm{B})\right)$ is rw-closed set in $(Y, \sigma)$. That is $f(B)$ is rw-closed in $(Y, \sigma)$, since $f$ is injective. Therefore $\mathrm{f}$ is rw-closed.

iii) Let $c$ be a closed set of $(Y, \sigma)$. Since $f$ is $g$ continuous, $\mathrm{f}^{-1}(\mathrm{c})$ is g-closed set in $(\mathrm{X}, \tau)$. Since $(\mathrm{X}, \tau)$ is a $T_{1 / 2}$-space, $f^{-1}(c)$ is closed set in $(X, \tau)$. Since $g^{\circ}$ $\mathrm{f}$ is rw-closed $\left(\mathrm{g}^{\circ} \mathrm{f}\right)\left(\mathrm{f}^{-1}(\mathrm{c})\right)$ is rw-closed in $(\mathrm{Z}, \eta)$. That is $g(c)$ is rw-closed in $(Z, \eta)$, since $f$ is surjective. Therefore $\mathrm{g}$ is rw-closed.

4. Rw-open maps

Definition: 4.1 A map f: $(X, \tau) \rightarrow(Y, \sigma)$ is called a rwopen map if the image $f(A)$ is

rw-open in $(\mathrm{Y}, \sigma)$ for each open set $\mathrm{A}$ in $(\mathrm{X}, \tau)$

Theorem: 4.2 For any bijection map $\mathrm{f}:(\mathrm{X}, \tau) \rightarrow(\mathrm{Y}, \sigma)$ the following statements are equivalent.

i) $\quad \mathrm{f}^{-1}:(\mathrm{Y}, \sigma) \rightarrow(\mathrm{X}, \tau)$ is rw-continuous

ii) $\quad \mathrm{f}$ is rw-open map and

iii) $\quad f$ is rw-closed map.

Proof: (i) $\Rightarrow$ (ii) Let $U$ be an open set of $(X, \tau)$. By assumption, $\left(\mathrm{f}^{-1}\right)^{-1}(\mathrm{U})=\mathrm{f}(\mathrm{U})$ is rw-open in $(Y, \sigma)$ and so $f$ is rw-open. (ii) $\Rightarrow$ (iii) Let $F$ be a closed set of $(X, \tau)$. Then $F^{c}$ is open set in $(\mathrm{X}, \tau)$. By assumption

$\mathrm{f}\left(\mathrm{F}^{\mathrm{c}}\right)$ is rw-open in $(\mathrm{Y}, \sigma)$. That is $\mathrm{f}\left(\mathrm{F}^{\mathrm{c}}\right)=\mathrm{f}(\mathrm{F})^{\mathrm{c}}$ is rwopen in $(Y, \sigma)$ and therefore $f(F)$ is rw-closed in $(Y, \sigma)$. Hence $F$ is rw-closed. (iii) $\Rightarrow$ (i) Let $\mathrm{F}$ be a closed set of $(\mathrm{X}, \tau)$. By assumption, $\mathrm{f}(\mathrm{F})$ is rw-closed in $(\mathrm{Y}, \sigma)$. But $\mathrm{f}(\mathrm{F})=\left(\mathrm{f}^{-}\right.$ $\left.{ }^{1}\right)^{-1}(\mathrm{~F})$ and therefore $\mathrm{f}^{-1}$ is continuous.

Theorem: 4.3 A map $\mathrm{f:}(\mathrm{X}, \tau) \rightarrow(\mathrm{Y}, \sigma)$ is rw-open if and only if for any subset $\mathrm{S}$ of $(\mathrm{Y}, \sigma)$ and any closed set of $(\mathrm{X}, \tau)$ containing $\mathrm{f}^{-1}(\mathrm{~S})$, there exists a rw-closed set $\mathrm{K}$ of $(\mathrm{Y}, \sigma)$ containing $\mathrm{S}$ such that $\mathrm{f}^{-1}(\mathrm{~K}) \subset \mathrm{F}$.

Proof: Suppose $f$ is rw-open map. Let $S \subset Y$ and $F$ be a closed set of $(X, \tau)$ such that $f^{-1}(S) \subset F$. Now $X-F$ is an open set in $(X, \tau)$. Since $f$ is rw-open map, $f(X-F)$ is rw-open set in $(\mathrm{Y}, \sigma)$. Then $\mathrm{K}=\mathrm{Y}-\mathrm{f}(\mathrm{X}-\mathrm{F})$ is a rwclosed set in $(\mathrm{Y}, \sigma)$. Note that $\mathrm{f}^{-1}(\mathrm{~S}) \subset \mathrm{F}$ implies $\mathrm{S} \subset \mathrm{K}$ and $\mathrm{f}^{-1}(\mathrm{~K})=\mathrm{X}-\mathrm{f}^{-1}(\mathrm{X}-\mathrm{F}) \subset \mathrm{X}-(\mathrm{X}-\mathrm{F})=\mathrm{F}$. That is $\mathrm{f}^{-1}(\mathrm{~K}) \subset \mathrm{F}$.

For the converse let $\mathrm{U}$ be an open set of $(\mathrm{X}, \tau)$. Then $\mathrm{f}^{-1}\left((\mathrm{f}(\mathrm{U}))^{\mathrm{c}}\right) \subset \mathrm{U}^{\mathrm{c}}$ and $\mathrm{U}^{\mathrm{c}}$ is a closed set in
$(\mathrm{X}, \tau)$. By hypothesis, there exists a rw-closed set $\mathrm{K}$ of $(\mathrm{Y}, \sigma)$ such that $(\mathrm{f}(\mathrm{U}))^{\mathrm{c}} \subset \mathrm{K}$ and $\mathrm{f}^{-1}(\mathrm{~K}) \subset \mathrm{U}^{\mathrm{c}}$ and so $\mathrm{U} \subset\left(\mathrm{f}^{-1}(\mathrm{~K})\right)^{\mathrm{c}}$. Hence $\mathrm{K}^{\mathrm{c}} \subset \mathrm{f}(\mathrm{U}) \subset \mathrm{f}\left(\left(\mathrm{f}^{-1}(\mathrm{~K})\right)\right)^{\mathrm{c}}$ which implies $f(U)=K^{c}$. Since $K^{c}$ is a rw-open, $f(U)$ is rwopen in $(Y, \sigma)$ and therefore $\mathrm{f}$ is rw-open map.

\section{REFERENCES}

[1] Arockiarani. I, Studies on generalizations of generalized closed sets and maps in topological spaces, Ph.D., Thesis, Bharathiar Univ., Coimbatore, 1997.

[2] Benchalli.S.S and Wali.R.S., On R $\omega$-closed sets in topological spaces, Bull.Malays.math.Sci.Soc(2) 30(2) (2007), 99-110.

[3] Gnanambal Y, On Generalized Pre-regular Closed sets in Topological Spaces, Indian J.Pure Appl.Math.,28(1997), 351-360.

[4] Long P.E, and Herington L.L, Basic properties of Regular Closed Functions, Rend.Cir.Mat.Palermo, 27(1978), 20-28.

[5] Malghan S.R, Generalized Closed maps, J.Karnatk Univ.Sci.,27(1982), 82-88

[6] Nagaveni N, Studies on Generalizations of Homeomorphisms in Topological spaces, Ph.D., Thesis, Bharathiar University, Coimbatore(1999).

[7] Palaniappan N and Rao K C, Regular generalized closed sets, Kyungpook Math. J. 33(1993), 211-219

[8] Sheik John M, A Study on Generalizations of Closed Sets on Continuous maps in Topological and Bitopological Spaces, Ph.D, Thesis Bharathiar University, Coimbatore,(2002)

[9] Sundaram P and Sheik John M, On w-closed sets in topology, Acta Ciencia Indica 4(2000), 389392

[10] Sundaram P, Studies on Generalizations of Continuous Maps in Topological Spaces, Ph.D, Thesis, Bharathiar University, Coimbatore,(1991).

[11] Vadivel A and Vairamanickam K, rg $\alpha$-Closed Sets and rg $\alpha$-Open Sets in Topological spaces, Int.Journal of Math.Analysis, Vol.3, 2009, no.37, 1803-1819.

[12] Vadivel A and Vairamanickam K, rgo-Closed and rg $\alpha$-Open Maps in Topological spaces, Int.Journal of Math.Analysis, Vol.4, 2010, no.10, 453-468 